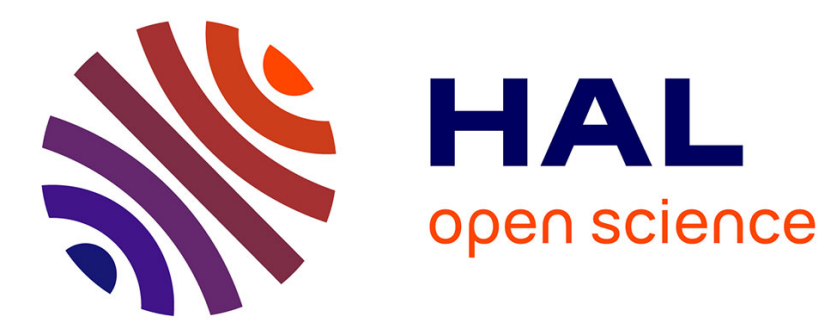

\title{
Positional cloning of disease resistance genes in grapevine
}

Claire Anderson, Nathalie Choisne, Anne-Francoise A.-F. Adam-Blondon, Ian B. Dry

\section{- To cite this version:}

Claire Anderson, Nathalie Choisne, Anne-Francoise A.-F. Adam-Blondon, Ian B. Dry. Positional cloning of disease resistance genes in grapevine. Genetics, Genomics, and Breeding of Grapes, Sciences Publishers, 390 p., 2011, 978-1-57808-717-4. hal-02807683

\section{HAL Id: hal-02807683 \\ https://hal.inrae.fr/hal-02807683}

Submitted on 6 Jun 2020

HAL is a multi-disciplinary open access archive for the deposit and dissemination of scientific research documents, whether they are published or not. The documents may come from teaching and research institutions in France or abroad, or from public or private research centers.
L'archive ouverte pluridisciplinaire HAL, est destinée au dépôt et à la diffusion de documents scientifiques de niveau recherche, publiés ou non, émanant des établissements d'enseignement et de recherche français ou étrangers, des laboratoires publics ou privés. 


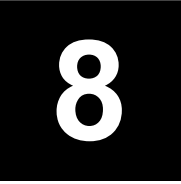

\title{
Positional Cloning of Disease Resistance Genes in Grapevine
}

\author{
Claire Anderson, ${ }^{1, \#}$ Nathalie Choisne ${ }^{2}$ Anne-Françoise \\ Adam-Blondon ${ }^{3}$ and Ian B. Dry ${ }^{1, *}$
}

\begin{abstract}
The introduction of genes that confer resistance to major grapevine pests and pathogens into the highly susceptible $V$. vinifera cultivars used for wine production worldwide would be of significant economic and environmental benefit. The availability of genetic resources for grapevine has led to a dramatic increase in research on the mapping of resistance loci. Often the outcome of this work is the development of markers for marker-assisted selection of new disease-resistant interspecific hybrids. However, positional cloning of these resistance genes offers the possibility to introduce these genes into existing elite wine grape cultivars by grapevine transformation without affecting wine quality which has been a major obstacle in the adoption of hybrid vines generated by classical breeding. Furthermore positional cloning offers the possibility to introduce resistance genes into $V$. vinifera cultivars from species which cannot be achieved through hybridization. Finally, cloning of resistance genes provides sequence information that can be used to design perfect genetic markers which will maximize the efficiency of marker assisted selection approaches. This chapter describes the strategy used, and technical challenges encountered, during the mapping and positional cloning of powdery mildew and
\end{abstract}

\footnotetext{
${ }^{1}$ CSIRO Plant Industry, Waite Campus, Hartley Grove, Urrbrae, SA 5060, Australia.

${ }^{2}$ Genoscope IG-CEA, UMR CNRS-INRA-Univ Evry Research in Plant Genomics, 2 rue Gaston Crémieux, BP 5708, 91057 Evry cedex, France.

${ }^{3}$ UMR INRA UEVE ERL CNRS Génomique Végétale, 2 rue Gaston Crémieux, BP 5708, 91 057, Evry cedex, France.

*Corresponding author: ian.dry@csiro.au

"Present address: School of Forest Resources and Conservation, University of Florida, Gainesville, FL 2611, USA.
} 
downy mildew resistance genes from the wild North American grape species Muscadinia rotundifolia.

Keywords: powdery mildew, downy mildew, resistance gene, positional cloning, Muscadinia rotundifolia

\subsection{Introduction}

The identification of plant genes by positional cloning is a lengthy process that requires a number of steps to be performed. Firstly, a mapping population must be constructed in which the gene of interest segregates in a genetically defined ratio. The mapping population can then be used to identify genetic markers linked to the locus of interest, enabling construction of a local genetic map. Conversion of the genetic map into a physical map requires a large-insert genomic library that can be used for chromosome walking or, as has become possible in recent years, the availability of a complete genome sequence. Finally, candidate genes identified in the interval between the genetic markers most closely flanking the locus of interest, must be tested by complementation to identify the functional gene.

Due to the considerable effort required, the positional cloning projects initiated in the late 20th century concentrated on largely important agricultural traits, such as those conferring disease resistance to agriculturally important plant pathogens. The first plant gene identified by positional cloning was the Pto gene of tomato (Martin et al. 1993) and its identification required the time-consuming development of introgressed genetic stocks and extensive marker development (Bortiri et al. 2006). Pto is a single dominant gene that confers resistance to the bacterial speck pathogen, Pseudomonas syringae pv. tomato and is an example of a gene that confers disease resistance in a "gene-for-gene" manner. Gene-for-gene resistance (Flor 1971) is a highly effective mechanism that relies on the direct, or indirect interaction, of the products encoded by a resistance gene in the plant and an avirulence gene in the pathogen. The interaction is highly specific and results in the activation of a suite of plant defence responses that culminate in localized cell death, called a hypersensitive response, at the site of attempted infection (Mur et al. 2008). This mechanism is most effective against biotrophic pathogens that require living tissue upon which to survive and gene-for-gene interactions have been described between plants and a wide variety of pathogen types, including bacteria, viruses, fungi, oomycetes, nematodes and aphids. Due to their strong effect and single gene basis, the isolation of plant resistance genes was a major goal of early positional cloning efforts. 
Since the identification of $P$ to, over 50 plant resistance genes have been mapped and cloned from a range of plant species (Martin et al. 2003; van Ooijen et al. 2007) including woody perennials such as apple (Belfanti et al. 2004; Malnoy et al. 2008). However, we now recognize that gene-for-gene resistance is the second of two distinct mechanisms that plants use to defend themselves against pathogens. The first layer of defence is termed basal immunity, or non-host resistance, and comprises of both the preformed chemical and physical barriers that prevent pathogen penetration and the inducible immune response that can be triggered upon plant recognition of microbe-associated molecular patterns (MAMPs; reviewed in Bent and Mackey 2007). The genetic basis of resistance mediated by preformed chemical and physical barriers is likely to be complex, involving multiple loci. However, MAMP recognition is achieved by plant receptor-like kinase proteins (Chinchilla et al. 2006; Zipfel et al. 2006) that have a simple, single gene basis. Unlike avirulence (effector) proteins, which are only produced by certain races of the pathogen population, MAMPs are generic molecules forming a core component of the microorganism that cannot be sacrificed or altered significantly without seriously impairing viability such as the chitin which makes up fungal cell walls (Bittel and Robatzek 2007). Receptor activation results in cytoskeletal rearrangements, callose deposition at the site of infection and the production of antimicrobial compounds, which can be an effective form of defence against both biotrophic pathogens that require living tissue upon which to survive and necrotrophic pathogens that feed off dead plant cells. Identification of the genes controlling these two important plant defence mechanisms could prove useful in strategies to improve the disease resistance of crop plants.

The threat of disease is of great concern to grapevine growers throughout the world. The European grape species, Vitis vinifera, is the most widely cultivated grapevine and produces berries of excellent quality. However, this species is highly susceptible to all major grapevine pathogens, including powdery mildew, caused by the fungus Erysiphe necator (syn. Uncinula necator), downy mildew, caused by the oomycete Plasmopara viticola, Pierce's disease, caused by the bacterium Xyllela fastidiosa, and phylloxera, caused by the insect Dactylosphaeria vitifolia (reviewed in Riaz et al. 2007) with only one known exception (Hoffmann et al. 2008). These, and other grapevine pathogens, have caused the near disappearance of viticulture in some areas of the world (Galet 1996) and are a major barrier to the growth of European grapevine species in areas such as the south-eastern USA, and Central and South America. Where grapevine production has persisted, the threat of disease is so great that extensive use of chemical fungicides is required, particularly to control the powdery and downy mildews. For example, a study of fungicide use in European Union member states (Phytowelt 
$\mathrm{GmbH} 2003$ ) concluded that while grapevines accounted for only 8\% of total crop production area, they accounted for $\sim 70 \%$ of all fungicides applied. This equates to costs of 150 and 75 million euros in France alone, for the chemicals used to control downy and powdery mildew, respectively, and does not take into account the increasing fuel costs associated with the application of these fungicides. Furthermore, fungal strains have been identified that have evolved resistance to a number of the commonly used fungicides (Erickson and Wilcox 1997; Savocchia et al. 2004; Baudoin et al. 2008) and it is now considered that the widespread use of agrochemicals is both environmentally detrimental and may pose a risk to human health. Consequently, the identification of genes that confer resistance to these pathogens and their incorporation into $V$. vinifera would be of significant economic and environmental benefit.

The susceptible nature of $V$. vinifera might be explained by the fact that this species arose in Europe and Asia, whereas many of the major grapevine pathogens such as powdery mildew, downy mildew and phylloxera are endemic to North America and were only introduced into Europe in the mid19th century (Boubals 1958, 1961, 1966). Therefore, V. vinifera has only been exposed to them for an extremely short period of time in evolutionary terms. In contrast, many grapevine species that are endemic to North America, display varying levels of resistance to these diseases. Although the potential exists to transfer resistance from these American relatives into $V$. vinifera cultivars, this has proven difficult to achieve by conventional breeding. One major constraint is that the North American grape species often have poor berry characteristics and, when hybrids have been generated, they lack the high berry quality of the original $V$. vinifera cultivar. The second constraint is that it is difficult to produce hybrids between $V$. vinifera and some of the most resistant American grapevines. For example, Muscadinia rotundifolia, a wild grapevine native to the south-eastern USA, is highly resistant to a number of pathogens known to affect cultivated grapevines, including powdery mildew, downy mildew, phylloxera and nematodes (Olmo 1986) and, as such, is a rich source of potential disease resistance genes. However, M. rotundifolia is taxonomically separated from Euvitis species by anatomical and morphological characteristics (Planchon 1887) and a difference in chromosome number (Vitis $2 n=38$, Muscadinia $2 n=40$; Branas 1932) and when the first attempts to produce interspecific crosses between $M$. rotundifolia and $V$. vinifera were performed in the mid-1800s they achieved only limited success. For these two reasons, the transfer of resistance genes into cultivated varieties by conventional breeding is still a major challenge for grapevine geneticists (Bisson et al. 2002). Consequently, a number of groups around the world are now interested in studying the North American grapevine species to determine the genetic basis of their 
disease resistance (Pauquet et al. 2001; Akkurt et al. 2006; WiedemannMerdinoglu et al. 2006; Welter et al. 2007; Chapter 1 Section 1.5.6) as this could lead to novel control methods by generating genetically modified grapevine cultivars.

\subsection{Positional Cloning of the Run1 and Rpv1 Genes}

\subsubsection{Development of Mapping Populations}

In 1998, we initiated a project to isolate two important resistance genes from $M$. rotundifolia by positional cloning. Despite the problems inherent in using $M$. rotundifolia as a source of resistance in grapevine breeding programs, Detjen (1919) was successful in producing authentic hybrids using $V$. vinifera $\mathrm{cv}$. Malaga as the female parent. This paved the way for construction of modern mapping populations, which is a crucial first step in any positional cloning effort. One of the hybrids produced, NC6-15, was used as the resistant parent in a series of pseudo-backcrosses (Bouquet 1986; Fig. 8-1). At each backcross step, a resistant individual was crossed with a different susceptible $V$. vinifera genotype to prevent inbreeding depression. This resulted in a number of populations from the fifth and sixth backcross generations in which resistance to powdery and downy mildew segregated in a 1:1 ratio. Complete resistance to powdery mildew was controlled by a single, dominant locus named Run1 (for resistance to Uncinula necator 1) and partial resistance to downy mildew was controlled by a major quantitative trait locus (QTL) named Rpv1 (for resistance to Plasmopora viticola 1; Bouquet 1986; Pauquet et al. 2001; Merdinoglu et al. 2003; Fig. 8-2). Interestingly, these two important resistance loci are co-located in the Muscadinia genome making them highly valuable targets that could be identified in a single positional cloning effort.

\subsubsection{Isolation of Genetic Markers Linked to the Run1 and Rpv1 Loci}

At the time the Run1/Rpv1 positional cloning project was conceived, limited genetic resources were available for grapevine and very few genetic markers existed. Therefore, we used three of our mapping populations, Mtp3294, Mtp3322 and Mtp3328 (Fig. 8-1), to identify novel markers that were linked to the resistance loci (Pauquet et al. 2001; Donald et al. 2002; Barker et al. 2005). A bulked segregant analysis approach (Michelmore et al. 1991) was initially used to identify amplified fragment length polymorphism (AFLP) markers that were linked to Run1. Pauquet et al. (2001) constructed bulks using the DNA of 10 individuals from the Mtp3294 population known to be resistant to powdery mildew (heterozygous for Run1) and 10 individuals 


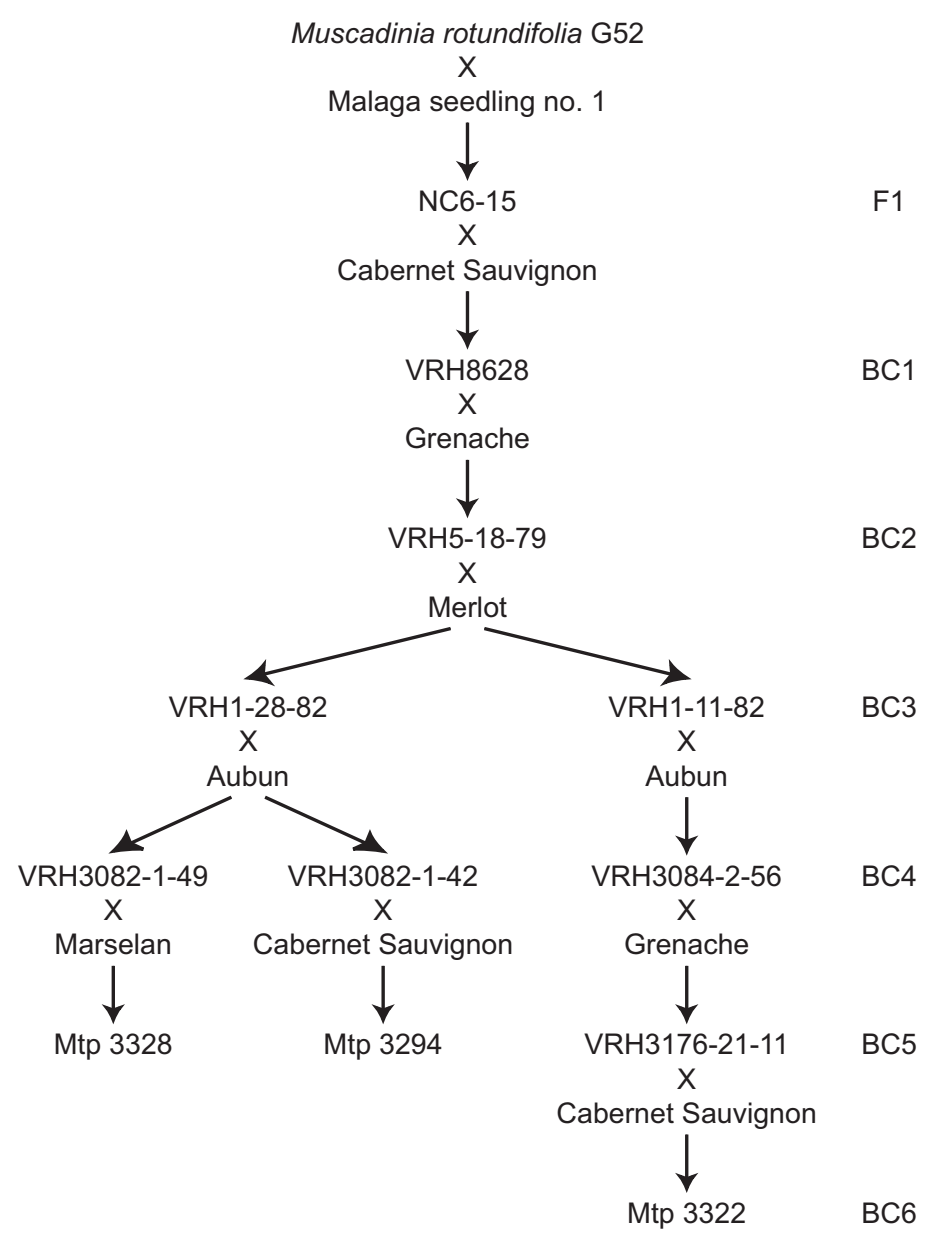

Figure 8-1 Parentage of mapping populations used to map the powdery and downy mildew resistance genes introgressed from $M$. rotundifolia $\mathrm{cv}$. $\mathrm{G} 52 . \mathrm{BC}_{\mathrm{n}}$ represents the pseudo-backcross step at which the individual was obtained.

known to be susceptible. Sixty four combinations of selective primers were then used to amplify fragments from the DNA pools and 19 polymorphic fragments were identified. To confirm linkage and determine marker order, each primer pair was used to amplify fragments from the genomic DNA of 157 individuals from the Mtp3294 population that had previously been challenged with powdery mildew. All 157 individuals from the Mtp3294 population were later also screened for resistance to downy mildew (P. viticola). Rpv1 was found to co-segregate with Run1 in all resistant progeny. This approach successfully identified 14 AFLP markers that were closely linked to the Run1/Rpv1 locus in VRH3082-1-42, of which 11 co-segregated with the resistance locus (Fig. 8-3). 


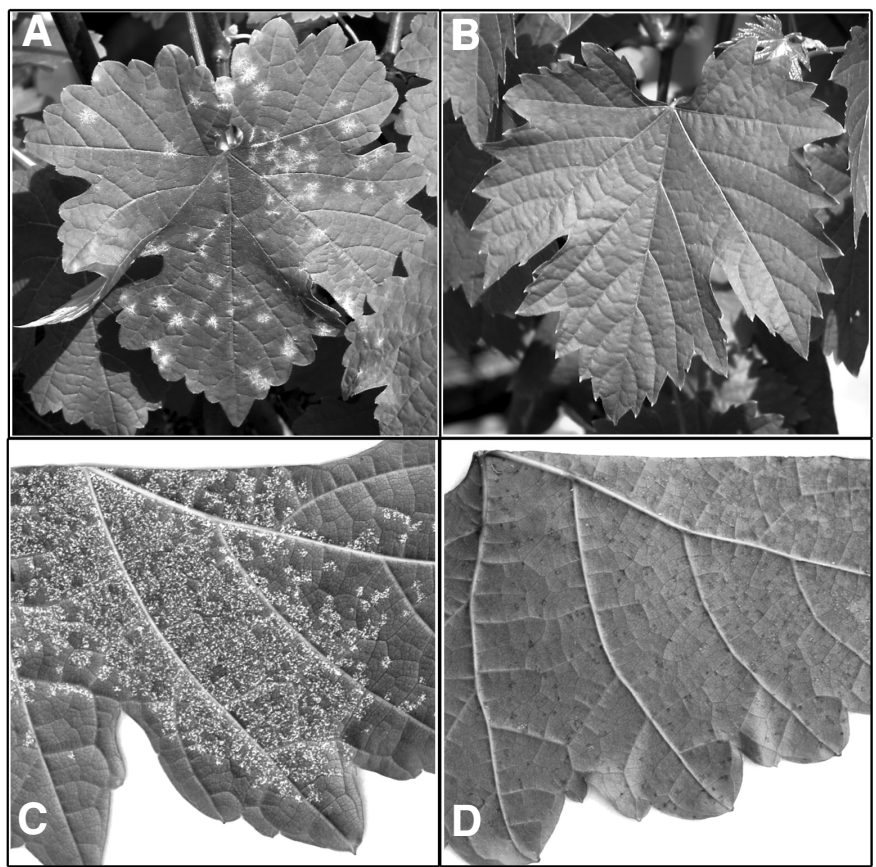

Figure 8-2 Comparison of powdery mildew (A, B) and downy mildew (C, D) susceptibility of leaves from $V$. vinifera $\mathrm{cv}$. Cabernet sauvignon $(\mathrm{A}, \mathrm{C})$ and from $M$. rotundifolia $\times$ V. vinifera 4th generation backcross (B, D). Powdery mildew growth is completely suppressed on the $\mathrm{BC}_{4}$ plant but a low level of downy mildew sporulation is supported on $\mathrm{BC}_{4}$ leaves. Patches of dead cells which have undergone programmed cell death in response to downy mildew infection are visible in panel $\mathrm{D}$.

Color image of this figure appears in the color plate section at the end of the book.

To supplement the genetic map produced using AFLPs, a second class of markers was sought that are unique to the study of plant disease resistance genes. Despite the fact that they confer resistance to a wide range of pathogen types, comparison of the plant resistance genes that contribute to gene-for-gene resistance has shown that the majority encode proteins with a central nucleotide binding site (NBS) linked to a C-terminal leucinerich repeat (LRR) domain (reviewed in Takken et al. 2006). Motifs within the NBS are highly conserved and have been used to design degenerate primers capable of amplifying novel resistance gene analogs (RGAs) from many plant species (Aarts et al. 1998; Collins et al. 1998; Shen et al. 1998). Nested primers designed to four conserved amino acid motifs present in the NBS (GVGKTT (P-loop), L(I/V/L)VLDDV (kinase-2), GLPL and MHD) were used to amplify RGAs from the genome of a BC $_{4}$ (VRH3082-1-42) resistant individual (Donald et al. 2002). Twenty eight unique grapevine RGA sequences were identified and were subdivided into 22 groups of 


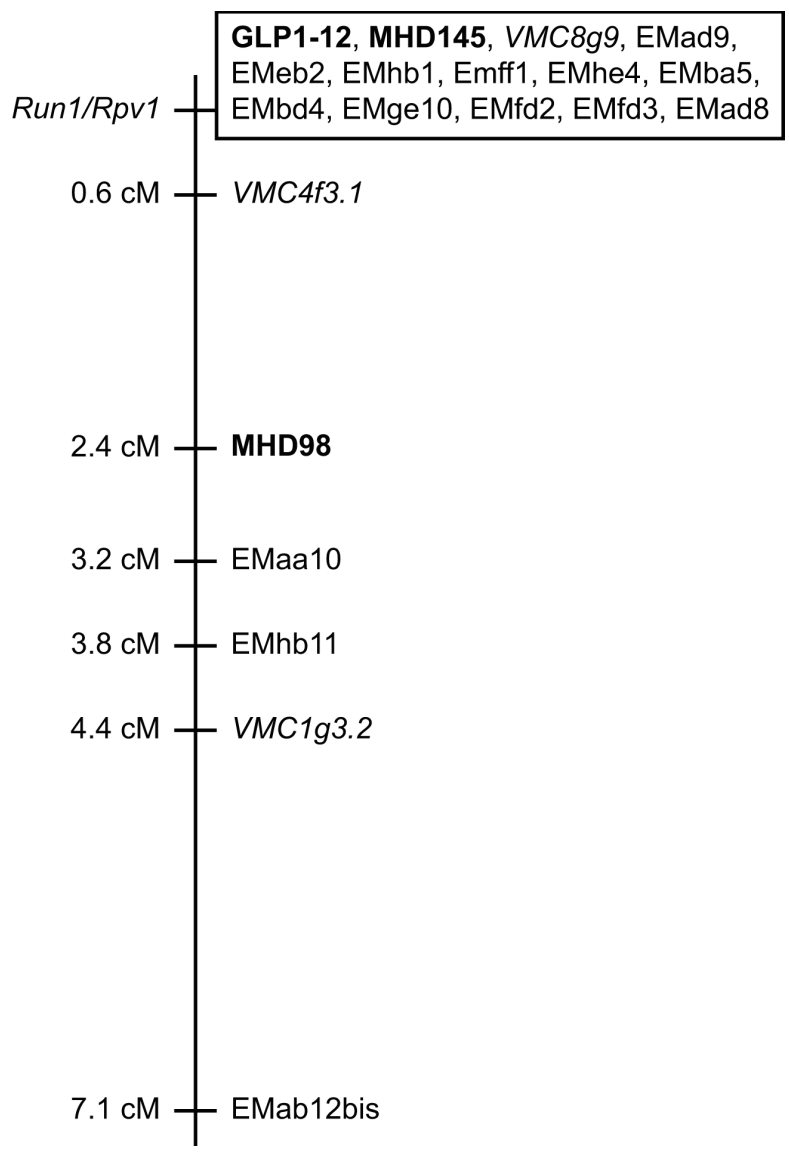

Figure 8-3 Genetic map of VRH3082-1-42 based on screening 160 individuals of Mtp3294 showing the location of SSR, AFLP and RGA markers linked to Run1/Rpv1 locus. RGA markers are shown in bold, SSR markers in italics.

sequences that showed nucleic acid sequence identity of $70 \%$ or greater. Representatives from each group were used in a bulked segregant analysis strategy to identify restriction fragment length polymorphisms (RFLPs) linked to the powdery mildew resistance locus. This led to the identification of three markers, MHD98, MHD145 and GLP1-12, for which linkage was subsequently confirmed by analyzing the RFLP patterns produced by a selection of powdery mildew-resistant and powdery mildew-susceptible individuals from the Mtp3294 population. To facilitate screening of the entire Mtp3294 mapping population, GLP1-12 was subsequently converted into a cleaved amplified polymorphic sequence (CAPS) marker and MHD98 was converted into a dominant, PCR-based marker (Donald et al. 2002). The three markers were then examined in 167 individuals in the Mtp 3294 
population, revealing that both GLP1-12 and MHD145 co-segregated with the Run1/Rpv1 locus (Fig. 8-3). A similar approach was used by Di Gaspero and Cipriani (2002) to identify RGA sequences from the grape species Vitis amurensis and Vitis riparia. These species are known to display resistance to downy mildew and one of the RGA clones identified, rgVrip064, was linked to a downy mildew resistance locus segregating in a hybrid population.

Three further markers were added to the local genetic map surrounding Run1 by searching for simple sequence repeat (SSR) markers that showed linkage to the resistance locus in the Mtp 3294 population (Barker et al. 2005) from those generated by the Vitis Microsatellite Consortium coordinated by Agrogène, France. Together, the data obtained by analysis of $\sim 160$ individuals from the Mtp3294 population generated a genetic map for the VRH3082-1-42 parent in which 14 markers co-segregated with Run1 (Fig. 8-3).

To further refine the genetic map surrounding the Run1/Rpv1 locus, an additional 419 individuals from the Mtp3322 population and 416 individuals from the Mtp3328 population were then examined (Barker et al. 2005). Mtp3322 was derived from a cross between the resistant parent, VRH317621-11 and the susceptible parent, V. vinifera cv. Cabernet Sauvignon. Mtp3328 was derived from a cross between the resistant parent, VRH3082-1-49 and the susceptible parent, $V$. vinifera cv. Marselan (Fig. 8-1). To facilitate scoring of AFLP markers, EMhb1 and EMfd3 were cloned and converted into the dominant, PCR-based marker Shb1 or the RFLP marker Sfd3, respectively. Once recombinant plants had been identified, they were phenotyped for powdery and downy mildew resistance and additional markers were scored. Two plants were identified that were recombinant between Run1/ Rpv1 and VMC8g9 and four plants were recombinant between Run1/Rpv1 and Shb1 (Table 8-1). This allowed a marker order to be assigned in which Run1/Rpv1 was located between the SSR markers, VMC4f3.1 and VMC8g9, an interval that was considered sufficiently small to enable map-based cloning of the Run1 and Rpv1 loci.

\subsection{Physical Mapping of the Run1/Rpv1 Locus}

\subsubsection{Generation of a Bacterial Artificial Chromosome library}

As no genome sequence currently exists for M. rotundifolia, we chose to isolate the Run1 and Rpv1 genes using a chromosome walking approach. This required construction of a large-insert genomic library containing the allele of interest. In recent years, bacterial artificial chromosome (BAC) vectors have become the vehicle of choice for the generation of such libraries due to the large size of fragments that can be cloned and their increased stability and ease of manipulation compared to other vectors 


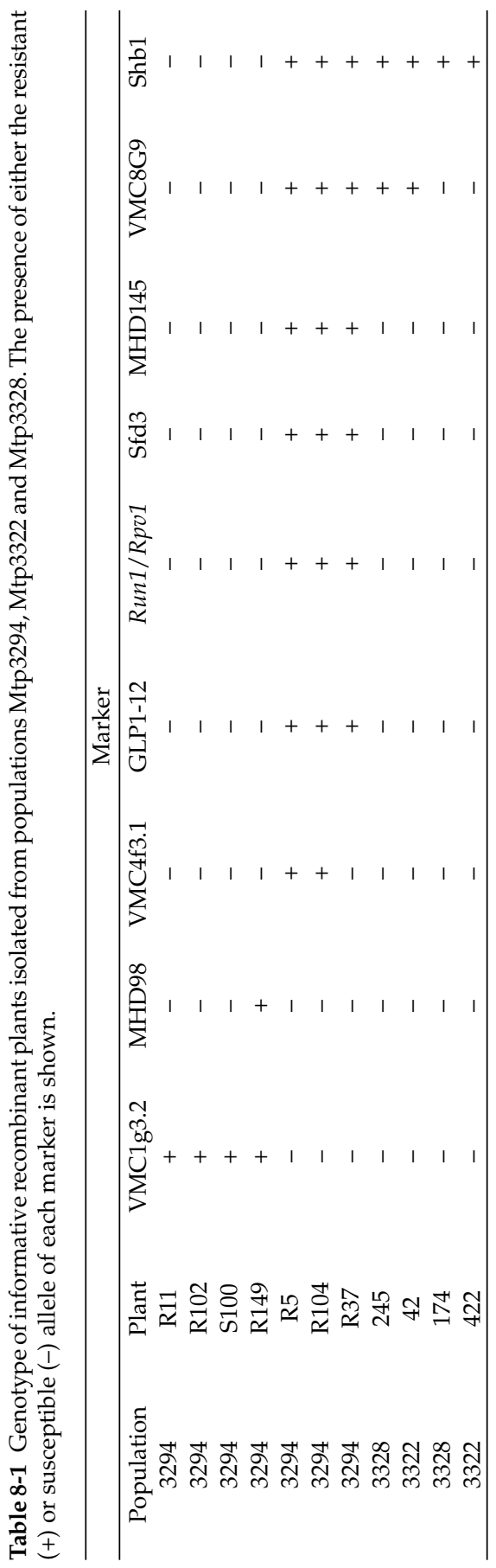


such as cosmids or yeast artificial chromosomes (Shizuya et al. 1992; Woo et al. 1994; Chapter 9 Section 9.2). A BAC library using the genomic DNA of a single powdery mildew-resistant plant from the Mtp3294 mapping population was generated (Barker et al. 2005). This individual was clonally propagated to generate sufficient leaf material for construction of the BAC library and megabase-sized DNA was extracted, digested with HindIII or $\mathrm{BamHI}$ and size-fractionated essentially as described by Peterson et al. (2000). The library was constructed in the pINDIGOBAC-5 vector (Epicentre, Madison, WI) and individual clones were stored in 144 x 384-well plates (Barker et al. 2005). The library contained a total of 55,295 clones with an estimated average insert size of $93 \mathrm{~kb}$. Less than $5 \%$ of clones did not contain an insert and approximately $1.7 \%$ of clones contained chloroplast-derived sequence as determined by hybridization of clones arrayed on a filter with the grapevine RNA polymerase B gene. Given that the grapevine genome has been estimated at $475 \mathrm{Mb}$ by flow cytometry (Lodhi and Reisch 1995) and $487 \mathrm{Mb}$ by genome sequencing (Jaillon et al. 2007), the library contains around 10 -fold haploid genome coverage.

\subsubsection{Assembly of BAC Contigs Containing Linked Genetic Markers}

To initiate a physical map of the region containing the Run1/Rpv1 locus, the BAC library was screened to identify clones containing three genetic markers that co-segregated with resistance (GLP1-12, MHD145 and Sfd3) and two flanking markers (VMC8g9 and VMC4f3.1). For VMC4f3.1, VMC8g9 and Sfd3, between seven and nine clones were isolated from the library, close to the expected representation of a single copy sequence in a library of predicted 10-fold genome coverage (Barker et al. 2005). In contrast, over 60 clones were identified that contained MHD145-hybridizing sequences and over 50 hybridized the GLP1-12 probe. This indicated that GLP1-12 and MHD145 might represent repeated elements, or gene families, present within the grapevine genome.

The individual plant chosen to generate the BAC library was heterozygous for Run1 and Rpv1. Therefore, once clones containing genetic markers had been identified, they were grouped into "resistant" and "susceptible" contigs representing the chromosome containing Run1/Rpv1 derived from the resistant parent, VRH3082-1-42, or the chromosome lacking Run1/Rpv1 derived from the susceptible parent, V. vinifera cv. Cabernet Sauvignon, respectively. Comparison of restriction digest patterns was used to determine overlap between BAC clones and alignments were confirmed by PCR using primers designed from BAC end sequences. These primers were also used to amplify PCR products from a selection of resistant and susceptible genotypes in the Mtp3294 population, enabling a large number

of dominant and co-dominant markers to be identified that were linked to 
Run1 and Rpv1. Primers that amplified products of identical size from both resistant and susceptible genotypes were used to directly sequence BAC clones that contained the region of interest. Alignment of sequences enabled polymorphic nucleotides to be identified that could be utilized to generate CAPS markers. Primers were then used to isolate overlapping clones that could be used to extend BAC contigs (Fig. 8-4).

\subsubsection{Assembly of BAC Contigs Containing Resistance Gene Candidates}

GLP1-12 and MHD145 were originally identified as RFLP markers (Donald et al. 2002). Therefore, BACs containing these sequences were examined by RFLP analysis, enabling them to be grouped into contigs representing the resistant or susceptible chromosomes (Barker et al. 2005). Out of 49 clones examined, only two overlapping BACs were identified that contained the $2.2 \mathrm{~kb}$ MHD145-hybridizing EcoRI fragment characteristic of resistant plants. These BACs contained additional MHD145-hybridizing fragments, suggesting that each clone might contain multiple copies of a related sequence. By comparing EcoRI digests and RFLP patterns, other MHD145hybridizing BACs could be aligned with those containing the fragments characteristic of the co-dominant marker and overlap between clones was confirmed by PCR amplification using primers designed from BAC end sequences. Three BACs containing MHD145-hybridizing sequences were assembled into each of the resistant and susceptible contigs. Additional markers designed using BAC end sequence information confirmed that the two contigs were haplotypes and allowed overlapping BAC clones to be identified to extend the contigs.

Out of 43 GLP1-12-hybridizing BACs examined, six contained the 1.6 $\mathrm{kb}$ EcoRI fragment characteristic of resistant plants. However, in this case the BAC clones did not directly overlap, suggesting that the hybridization signals observed upon RFLP analysis of genomic DNA might be contributed by multiple members of a gene family (Barker et al. 2005). Five out of six BACs containing the $1.6 \mathrm{~kb}$ EcoRI fragment (4M9, 26C5, 61L18, 69D12 and 101P19; Fig. 8-4) were assembled into one contig using restriction fragment digest patterns and PCR products amplified using BAC end-derived primers (Barker et al. 2005). However, the sixth BAC containing the characteristic RFLP fragment (97A19; Fig. 8-4) did not overlap the main GLP1-12containing contig, despite the fact that primers designed using $\mathrm{BAC}$ end sequence from this clone (CB33.34) could be used as a PCR-based marker that co-segregated with Run1 and Rpv1. Therefore, both the main GLP1-12containing contig and 97A19 were used to initiate chromosome walks.

Extension of the main GLP1-12-containing contig allowed identification of five overlapping BAC clones (7D20, 19G13, 87P7, 130N7 and 134D9) that 
198 Genetics, Genomics and Breeding of Grapes
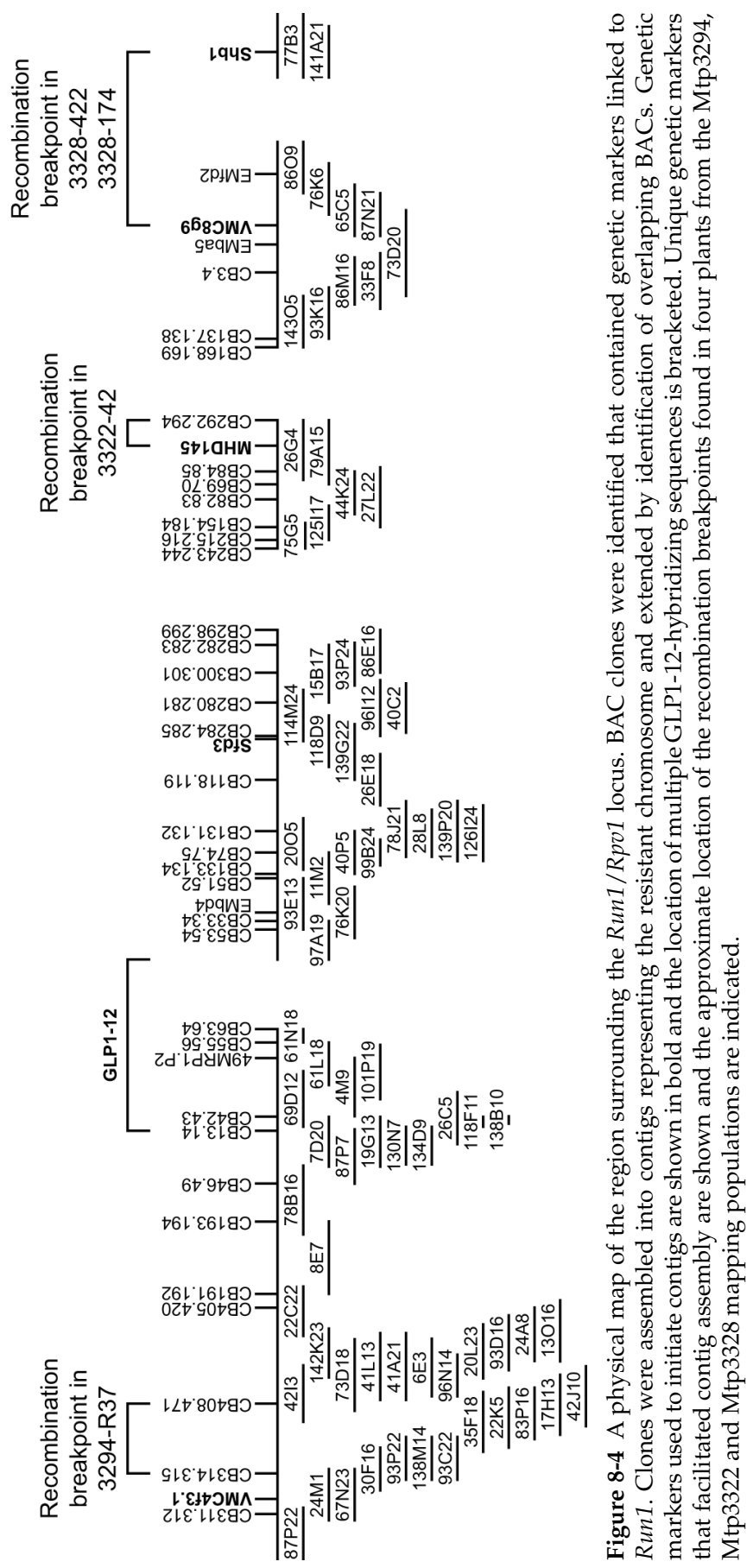
contained additional GLP1-12-hybridizing sequences. By RFLP analysis of PCR products amplified from all GLP1-12-hybridizing BACs in the contig, Barker et al. (2005) showed that this region contained at least four members of a gene family. PCR-based markers designed from BAC end sequences were used to identify additional overlapping BACs. Although none of the BACs added to the contig beyond 87P7 contained GLP1-12-hybridizing sequences, the contig eventually spanned the region between GLP1-12 and the SSR marker, VMC4f3.1, providing evidence that these two markers were adjacent in the genome.

No clones were present in our BAC library that could extend the main GLP1-12 contig beyond 61N18. Similarly, no clones were identified that overlapped the right-hand BAC end of 97A19. However, two overlapping BACs were identified using the PCR-based marker CB33.34 that had been designed from the left-hand BAC end sequence of 97A19. A further 16 clones were added to this contig, resulting in an assembly of 19 BAC clones that formed a contiguous region from 97A19 to 86E16. This region contained both the AFLP marker EMbd4, as determined using primers designed from the cloned AFLP sequence, and the RFLP marker Sfd3.

\subsubsection{Genetic Mapping using BAC-derived Markers}

A large number of new genetic markers were identified during the physical mapping process. Therefore, all Mtp3294, Mtp3322 and Mtp3328 progeny that had been identified as recombinant between VMC4f3.1 and Shb1 were retested using the panel of new BAC end sequence-derived markers. This identified recombination breakpoints in 3328-422 and 3328-174 between VMC8g9 and Shb1, which allowed the orientation of the VMC8g9 contig to be determined. The recombination breakpoint in 3322-42 was located between markers MHD145 and CB292.294, which allowed orientation of the MHD145 contig and confirmed its placement between Sfd3 and VMC8g9 (Barker et al. 2005). The recombination breakpoint in 3294-R37 was located between CB314.315 and CB407.471 which, when taken together with the information obtained from 3322-42, suggests that Run1 and Rpv1 are located in the interval between CB314.315 and CB292.294 (Fig. 8-4).

\subsection{Technical Issues Associated with the Chromosome Walking Approach}

\subsubsection{Gaps in the BAC Library}

Despite the fact that our BAC library was equipped to contain 10-fold haploid genome coverage, it proved impossible to join the three major contigs containing VMC4f3.1, GLP1-12, Sfd3 and MHD145 (Fig. 8-4). 
The BAC library contained 49,920 clones generated using HindIII and 5,378 clones generated using BamHI. Therefore, gaps in the library could have been caused by bias in restriction site distribution as might occur in centromeres, telomeres and highly repetitive regions. For this reason it has been suggested that BAC libraries should be generated from genomic DNA that has been digested with a number of different restriction enzymes $(\mathrm{Wu}$ et al. 2004; Suetsugu et al. 2007), or randomly sheared (Osoegawa 2007), to improve representation of problematic and repeat-rich regions at telomeres and in centromeric heterochromatin.

To supplement our BAC library we made two additional libraries using genomic DNA from the same powdery mildew-resistant plant that had been used for BAC library construction. For both libraries, nuclei were prepared according to Peterson et al. (2000). The genomic DNA was then either mechanically sheared and cloned into a pWEB::TNC ${ }^{\mathrm{TM}}$ cosmid vector (Epicentre, Madison, USA) or partially digested with Sau3AI and cloned into a $\lambda$ Blue STAR lambda vector (Novagen, Madison, USA) according to the individual manufacturer's protocols. The cosmid library contained 148,400 clones with an average insert size of $35.3 \mathrm{~kb}$ and the lambda library contained 395,600 clones with an average insert size of $12 \mathrm{~kb}$. However, despite the fact that these two libraries contained approximately 11-fold and 10-fold genome coverage respectively, when the libraries were screened with BAC end sequences for which no overlapping BAC clones could be found, these sequences were also missing from the cosmid and lambda libraries. This suggested that the lack of representation of clones in this region might be caused by clone instability or lethality, rather than restriction enzyme bias.

Evidence of clone instability was obtained when the gap in the GLP1-12 contig was examined in more detail. When the BAC library was screened with the BAC end marker CB55.56 (derived from clone 61L18) to find overlapping BACs, only one additional clone was identified in the library. This BAC clone, $82 \mathrm{O} 20$, contained an insert of $31.5 \mathrm{~kb}$ which was significantly smaller than the average BAC library insert size of $93 \mathrm{~kb}$. Upon sequencing $82 \mathrm{O} 20$, it became apparent that while it contained large regions of homologous sequence to 61L18, these two clones did not overlap (Fig. 8-5). The BAC library was rescreened with a new marker designed to the end of $82 \mathrm{O} 20$ (CB63.64) and this identified BAC clone $61 \mathrm{~N} 18$ which was also unusually short $(31.4 \mathrm{~kb})$ and which again did not overlap. A further marker (CB90.488) was designed to the end of 61N18. This marker did not identify any new clones in the BAC library, but a $40 \mathrm{~kb}$ clone (Cos106A) was identified in the cosmid library. Sequence comparison of BAC clones $61 \mathrm{~L} 18,61 \mathrm{~N} 18,82 \mathrm{O} 20$ and cosmid clone Cos106A indicated the presence of large regions of DNA sequence that is locally repeated in the $M$. rotundifoliaderived introgression (Fig. 8-5). 


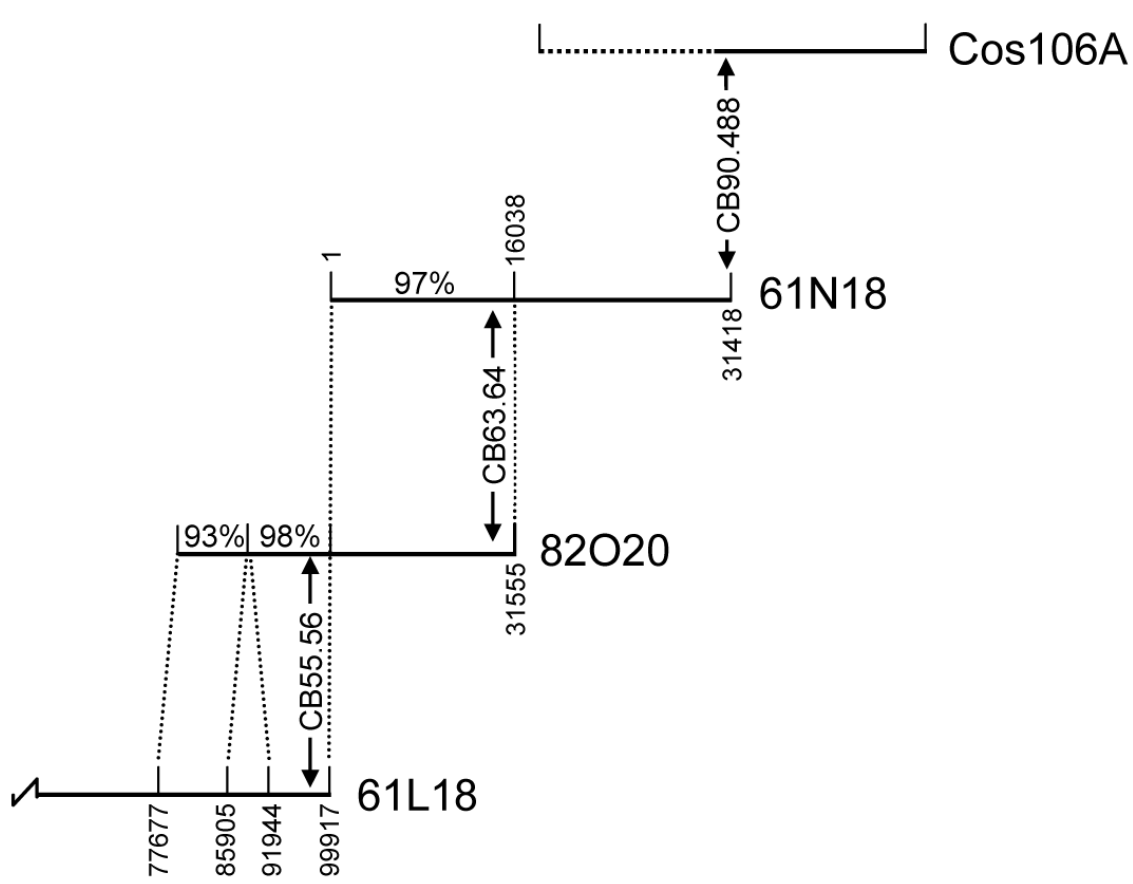

Figure 8-5 Homology of BAC and cosmid clones that contain repeated DNA. The identity and position of primers used to screen for overlapping clones (as outlined in the text) are shown by arrows. The percentage nucleotide identity and position of homologous regions within the clones are indicated. Only approximately half of Cos106A (solid line) could be successfully sequenced. Primers CB90.488 amplified a $1 \mathrm{~kb}$ fragment from Cos106A that was $99 \%$ identical to the sequence from $61 \mathrm{~N} 18$. BAC clones $61 \mathrm{~L} 18$ and $61 \mathrm{~N} 18$ were subsequently demonstrated to be adjacent within the genome as shown in Fig. 8-4.

The small insert size of BAC clones $82 \mathrm{O} 20$ and $61 \mathrm{~N} 18$ compared to the average insert size of our library also suggested that these clones contained sequences that have caused rearrangement and deletion during culture. Cosmid clone Cos106A also proved to be highly unstable and the estimated $40 \mathrm{~kb}$ insert in this clone would spontaneously and unpredictably revert to an approximately $15 \mathrm{~kb}$ insert in culture. Sequencing of this clone proved to be extremely difficult and assembly was hampered by the presence of numerous repeated sequences, including a partial tandem repeat $45 \mathrm{~S}$ rDNA unit (Fig. 8-6). Eukaryotes generally have many copies of rDNA organized in tandem repeats (Lafontaine and Tollervey 2006) and it has been shown that BAC clones containing tandemly repeated DNA elements are not stable and can undergo drastic deletions during routine library maintenance and DNA preparation (Song et al. 2001). The presence of these tandem repeat units within the genome may therefore explain at least some of the gaps observed in the contig assembly. 


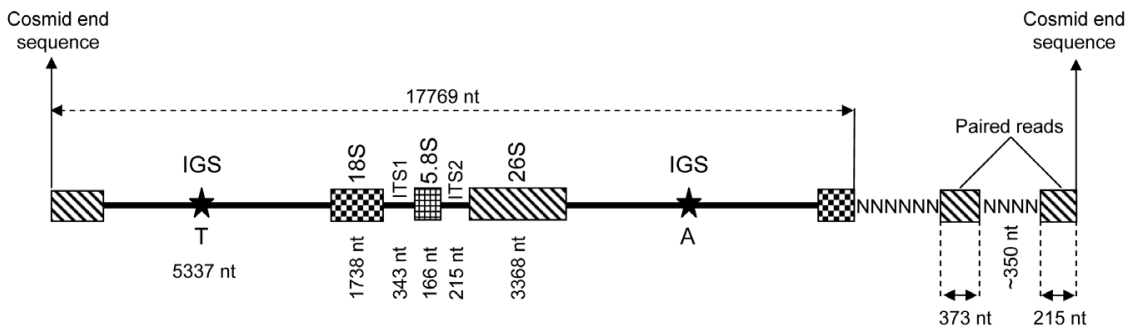

Figure 8-6 Sequence assembly of Cos106A using PHRED, PHRAP and in-house Genoscope programs taking into account paired reads and a manual curation of the repeated sequences. The sequence obtained corresponded to a partial tandem repeat of a $45 \mathrm{~S}$ rDNA unit. N's indicate where joining sequence could not be resolved. Abbreviations: IGS: InterGenic Spacer; ITS: Internally transcribed spacer.

\subsubsection{Lack of Correlation between Physical and Genetic Distance}

Our genetic mapping studies indicated that the Run1/Rpv1 locus is located in the interval between the SSR markers, VMC4f3.1 and VMC8g9. These two markers were placed just $0.6 \mathrm{cM}$ apart in the local genetic map of VRH3082-1-42, the resistant parent of the Mtp3294 mapping population (Fig. 3; Barker et al. 2005), suggesting that either the markers were located physically close to one another in the grapevine genome, or that recombination rates were unusually low in this region. Riaz et al. (2004) and Adam-Blondon et al. (2004) have produced genome linkage maps for $V$. vinifera that span 1,728 cM and 2,200 cM, respectively. Given that the grapevine genome has been estimated at $475-487 \mathrm{Mb}$ (Lodhi and Reisch 1995; Jaillon et al. 2007), this predicts that on average $1 \mathrm{cM}$ is equivalent to 216-282 kb. Thus, the interval between VMC4f3.1 and VMC8g9 should be approximately 130-169 kb. However, as contigs spanning well over $1 \mathrm{Mb}$ were constructed, this is clearly not the case. Indeed, the actual estimated physical distance between VMC4f3.1 and VMC8g9, based on alignments of the sequenced BAC contigs with the current version of the Vitis genome sequence (improved from Jaillon et al. 2007) is approximately 5.4 Mbp (N. Choisne, unpublished results).

Reduced recombination frequencies have been observed around resistance loci in wheat, barley and poplar where resistance has been introduced via an introgressed region from a related species (Wei et al. 1999; Stirling et al. 2001; Neu et al. 2002). Therefore, the dramatically reduced recombination rate in the vicinity of Run1 might be due to the presence of divergent DNA contributed by the introgression from M. rotundifolia. The implication of low recombination frequencies in this region for future isolation of the Run1 gene is that large populations may be required in order to obtain sufficient recombinant individuals to delineate the resistance locus with suitable precision. 


\subsection{Fine Mapping of the Run1/Rpv1 Locus and Functional Evaluation of Candidate Resistance Genes}

As the physical distance between VMC4f3.1 and VMC8g9 was clearly much greater than the genetic distance had suggested, extended mapping populations were examined to identify rare recombinants that would allow the Run1 and Rpv1 loci to be delineated with greater precision. To achieve this, a further 3,300 progeny of the Mtp3294 and Mtp3322 populations (Fig. 8-1) were generated and screened for recombination between the markers 49MRP1.P2, CB69.70 and CB137.138 (Fig. 8-4) using a highthroughput multiplex PCR system. This identified 21 plants in which a recombination event was observed between the markers of interest. The reaction of these recombinant plants to powdery and downy mildew was determined, allowing the location of Run1 and Rpv1 to be localized to a $\sim 1 \mathrm{Mb}$ region of introgressed DNA. Sequencing of this region has revealed the presence of a cluster of 11 resistance gene analogs (RGAs) encoding TIR-NBS-LRR type resistance proteins which are very similar in structure to the Mla powdery mildew resistance genes isolated from barley (Zhou et al. 2001). Seven of the RGAs encode full-length proteins which are highly homologous apart from a variable number of leucine-rich repeat domains and real-time expression analysis indicates that all of the RGA candidates are expressed in resistant progeny. Full-length genomic clones including the encompassing, the endogenous promoter and terminator regions of all seven RGA candidates are currently being transformed individually into powdery and downy mildew susceptible $V$. vinifera cultivars to determine which of the RGA candidates function as powdery or downy mildew resistance genes.

\subsection{The Future of Positional Cloning in Grapevine}

Manipulation of disease resistance is a major challenge to be met by grapevine geneticists (Bisson et al. 2002) and, as such, has been the first goal of fine mapping and map-based cloning approaches in grapevine (Table 8-2). In the future, we expect to see an increase in the application of positional cloning approaches for the identification of key genes involved in grapevine development (Fernandez et al. 2006) and adaptation to abiotic stress. Indeed, even in model species like Arabidopsis, where large collections of mutants are available which can be used to determine gene function, there are still many projects utilizing positional cloning techniques to gain an understanding of the genetic basis of trait variation (see as an example Loudet et al. 2003; Mouille et al. 2006).

Since the commencement of the Run1/Rpv1 mapping project, the availability of genetic resources for grapevine has improved dramatically. 


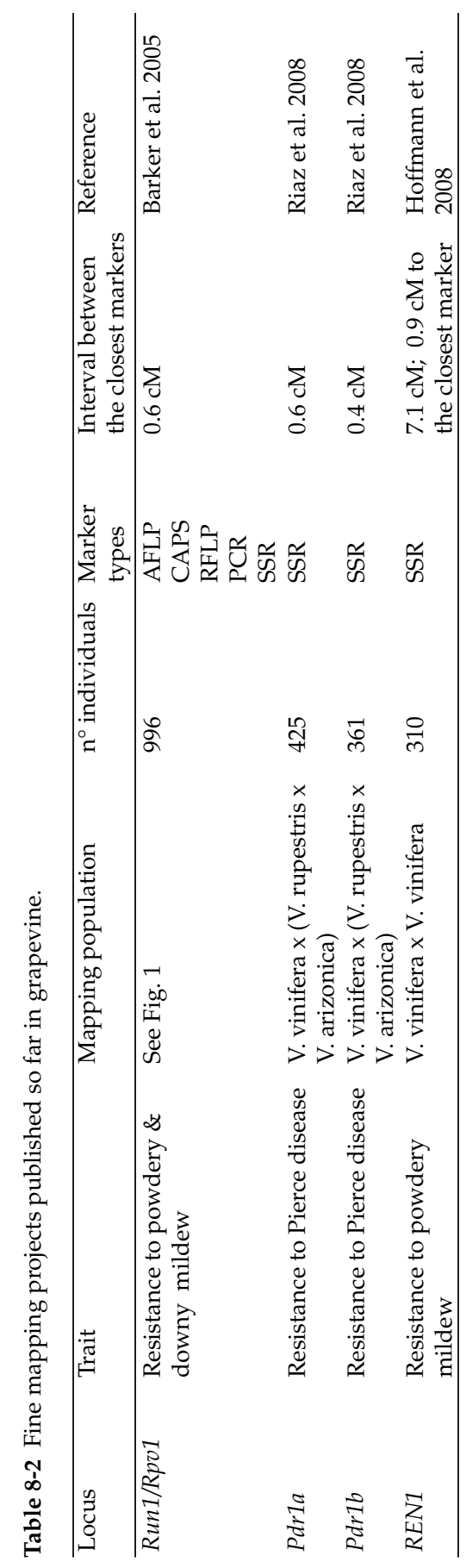


Comprehensive genome linkage maps have been constructed (AdamBlondon et al. 2004; Riaz et al. 2004) and a large number of SSR loci have been identified that are now the markers of choice for positional cloning projects due to their transferability between species. For example, Hoffmann et al. (2008) quickly localized a $V$. vinifera resistance gene to powdery mildew, REN1, in a $7.1 \mathrm{cM}$ interval by screening 195 well scattered SSR markers by bulk segregant analysis. The release of the complete $V$. vinifera genome sequence (Velasco et al. 2007; Jaillon et al. 2007) will also significantly increase the speed with which future genes of all types can be identified by positional cloning. However, as $V$. vinifera appears to be lacking resistance to many of the major pathogens, the published genome sequence can only act as a guide to the types of genes that may be present within the region of interest. Analysis of the $V$. vinifera genome sequence has revealed that many of the quantitative trait loci for resistance which have been mapped to date to disease co-localize with clusters of NBS-LRR genes (Di Gaspero et al. 2007; Moroldo et al. 2008). However, identification of the alleles conferring resistance will still require sequencing of the genome in question.

This then leads to the question of the most cost-efficient way to obtain genomic sequence from the species containing the gene of interest, i.e., library construction/chromosome walking or whole genome sequencing? With the continued development of new, cost-efficient sequencing technologies, it may ultimately be quicker and cheaper to sequence an entire genome rather than construct a BAC library, assemble a contig and sequence individual clones, as we have done. Furthermore, as the new sequencing technologies do not require cloned DNA, this will reduce the risk of gaps occurring due to clone instability / lethality. Therefore, it is possible that Run1 and Rpv1 may be the first and last grapevine genes isolated by chromosome walking. However, these new sequencing techniques are still not well suited to dealing with regions of highly repetitive DNA, which may still require construction of large insert libraries to resolve these regions.

Despite the tremendous improvements in genomic technologies over the last decade, the identification of unknown genes will still require significant resources and challenges in terms of the management of large populations of perennial plants, accurate phenotyping of traits, the generation of recombinant genotypes within the region of interest and the issue of non-homogeneous recombination rates within the genome. Most projects aiming at the identification of disease resistance genes will involve the generation of integrated genetic and physical maps in non-vinifera species, which will also generate interesting information about genome evolution in the Vitaceae family.

Unlike most other genes isolated from grapevine which can be functionally evaluated in model plants such as Arabidopsis, tobacco or tomato which are readily transformable, NBS-LRR type resistance genes 
which make up the majority of resistance genes within a plant species, show "restricted taxonomic functionality" (Michelmore 2003) which means they are only function within species of the same taxonomic family. Furthermore, many biotrophic pathogens such as E. necator and $P$. viticola are specifically adapted to the grapevine host and will not infect model plant species. This means that functional evaluation of most cloned candidate resistance genes will require this evaluation to be undertaken in transgenic grapevines, the generation of which remains a time-consuming and inefficient process. The development of highly efficient transient assay systems involving agroinfiltration (Santos-Rosa et al. 2008) or particle bombardment will be crucial for the rapid evaluation of resistance gene candidates in grapevine.

Finally, an important decision for researchers to make in the future will be whether to devote time and energy into cloning and functionally characterizing individual resistance genes, which can be used for genetic transformation of existing cultivars or alternatively whether to concentrate on the development of tightly-linked markers for use in classical breeding approaches such as marker-assisted selection. However, such a decision is more likely to be influenced by political and social issues associated with the adoption of transgenic vines for wine-making (discussed in Riaz et al. 2007; DeFrancesco 2008) rather than by the scientific merits of each approach.

\section{Acknowledgements}

The Australian component of this research is supported by the Grape and Wine Research and Development Corporation. The excellent technical assistance of Ange Jermakow, Karina Swann and Pat Corena in the generation of these results is gratefully acknowledged. We also wish to acknowledge the tremendous contribution of Alain Bouquet who initiated this project, produced all of the progeny populations used in the mapping studies and continued to contribute to the project through the generation of transgenic grapevines for functional analysis of the resistance gene candidates.

\section{References}

Aarts MGM, Lintel TE, Hekkert B, Holub EB, Beynon JL, Stiekema WJ, Pereira A (1998) Identification of R-gene homologous DNA fragments genetically linked to disease resistance loci in Arabidopsis thaliana. Mol Plant-Microbe Interact 11: 251-258.

Adam-Blondon A-F, Roux C, Claux D, Butterlin G, Merdinoglu D, This P (2004) Mapping 245 SSR markers on the Vitis vinifera genome: a tool for grape genetics. Theor Appl Genet 109: 1017-1027.

Akkurt M, Welter L, Maul E, Töpfer R, Zyprian E (2006) Development of SCAR markers linked to powdery mildew (Uncinula necator) resistance in grapevine (Vitis vinifera L. and Vitis sp.). Mol Breed 19: 103-111. 
Barker CL, Donald T, Pauquet J, Ratnaparkhe MB, Bouquet A, Adam-Blondon AF, Thomas MR, Dry IB (2005) Genetic and physical mapping of the grapevine powdery mildew resistance gene, Run1, using a bacterial artifcial chromosome library. Theor Appl Genet 111: 370-377.

Baudoin A, Olaya G, Delmotte F, Colcol JF, Sierotzki H (2008) QoI resistance of Plasmopara viticola and Erysiphe necator in the mid-Atlantic United States. Online. Plant Health Progress doi: 10.1094/PHP-2008-0211-02-RS.

Belfanti E, Silfverberg-Dilworth E, Tartarini S, Patocchi A, Barbieri M, Zhu J, Vinatzer BA, Gianfranceschi L, Gessler C, Sansavini S (2004) The HcrVf2 gene from a wild apple confers scab resistance to a transgenic cultivated variety. Proc Natl Acad Sci USA 101: 886-890.

Bent AF, Mackey D (2007) Elicitors, effectors, and R genes: the new paradigm and a lifetime supply of questions. Annu Rev Phytopathol 45: 399-436.

Bisson LF, Waterhouse AL, Ebeler SE, Walker MA, Lapsley JT (2002) The present and future of the international wine industry. Nature 418: 696-699.

Bittel P, Robatzek S (2007) Microbe-associated molecular patterns (MAMPs) probe plant immunity. Curr Opin Plant Biol 10: 335-341.

Bortiri E, Jackson D, Hake S (2006) Advances in maize genomics: the emergence of positional cloning. Curr Opin Plant Biol 9: 164-171.

Boubals D (1958) Contribution à l'étude des causes de la résistance des Vitacées au mildiou de la vigne (Plasmopara viticola (B and C) Berl. Et de T.) et de leur mode de transmission héréditaire. Ann Amélior Plantes 1: 1-236.

Boubals D (1961) Etude des causes de la résistance des Vitacées à l'oïdium de la vigne (Uncinula necator (Schw.) Burr.) et de leur mode de transmission héréditaire. Ann Amélior Plantes 11: 401-500.

Boubals D (1966) Etude de la distribution et des causes de la résistance au phylloxera redicicole chez les Vitacées. Ann Amélior Plantes 16: 145-184.

Bouquet A (1986) Introduction dans l'espèce Vitis vinifera L. d'un caractère de résistance à l'oidium (Uncinula necator Schw. Burr.) issu de l'espèce Muscadinia rotundifolia (Michx.) Small. Vignevini 12(suppl): 141-146.

Branas MM (1932) Sur la caryologie des Ampélidées. CR Acad Sci Paris 194: 121-123.

Chinchilla D, Bauer Z, Regenass M, Boller T, Felix G (2006) The Arabidopsis receptor kinase FLS2 binds flg22 and determines the specificity of flagellin perception. Plant Cell 18: 465-476.

Collins NC, Webb CA, Seah S, Ellis JG, Hulbert SH, Pryor A (1998) The isolation and mapping of disease resistance gene analogues in maize. Mol Plant-Microbe Interact 11: 968-978.

Detjen LR (1919) Some F1 hybrids of Vitis rotundifolia with related species and genera. North Carolina Agri Exp Stat Bull 18: 1-50.

DeFrancesco L (2008) Vintage genetic engineering. Nature Biotechnol 26: 261-263.

Di Gaspero G, Cipriani G (2002) Resistance gene analogs are candidate markers for diseaseresistance genes in grape (Vitis spp.). Theor Appl Genet 106: 163-172.

Di Gaspero G, Cipriani G, Adam-Blondon AF, Testolin R (2007) Linkage maps of grapevine displaying the chromosomal locations of 420 microsatellite markers and 82 markers from $R$-gene candidates. Theor Appl Genet 114: 1249-1263.

Donald TM, Pellerone F, Adam-Blondon A-F, Bouquet A, Thomas MR, Dry IB (2002) Identification of resistance gene analogs linked to a powdery mildew resistance locus in grapevine. Theor Appl Genet 104: 610-618.

Erickson EO, Wilcox WF (1997) Distributions of sensitivities to three sterol demethylation inhibitor fungicides among populations of Uncinula necator sensitive and resistant to triadimefon. Phytopathology 87: 784-791.

Fernandez L, Doligez A, Lopez G, Thomas MR, Bouquet A, Torregrosa L (2006) Somatic chimerism, genetic inheritance, and mapping of the fleshless berry (flb) mutation in grapevine (Vitis vinifera L.). Genome 49: 721-728.

Flor HH (1971) Current status of the gene-for-gene concept. Annu Rev Phytopathol 9: 275-276. 
Galet P (1996) Grape Diseases. Oeno Plurimedia Chaintre FranceHoffmann S, Di Gaspero G, Kovács L, Howard S, Kiss E, Galbács Z, Testolin R, Kozma P (2008) Resistance to Erysiphe necator in the grapevine 'Kishmish vatkana' is controlled by a single locus through restriction of hyphal growth. Theor Appl Genet 116: 427-438.

Hoffmann S, Di Gaspero G, Kovács L, Howard S, Kiss E, Galbács Z, Testolin R, Kozma P (2008) Resistance to Erysiphe necator in the grapevine 'Kishmish vatkana' is controlled by a single locus through restriction of hyphal growth. Theor Appl Genet 116: 427-438.

Jaillon O, Aury J-M, Noel B, Policriti A, Clepet C, Casagrande A, Choisne N, Aubourg S, Vitulo N, Jubin C, Vezzi A, Legeai F, Hugueney P, Dasilva C, Horner D, Mica E, Jublot D, Poulain J, Bruyere C, Billault A, Segurens B, Gouyvenoux M, Ugarte E, Cattonaro F, Anthouard V, Vico V, Del Fabbro C, Alaux M, Di Gaspero G, Dumas V, Felice N, Paillard S, Juman I, Moroldo M, Scalabrin S, Canaguier A, Le Clainche I, Malacrida G, Durand E, Pesole G, Laucou V, Chatelet P, Merdinoglu D, Delledonne M, Pezzotti M, Lecharny A, Scarpelli C, Artiguenave F, Pé E, Valle G, Morgante M, Caboche M, Adam-Blondon A-F, Weissenbach J, Quétier F, Wincker P (2007) The grapevine genome sequence suggests ancestral hexaploidization in major angiosperm phyla. Nature 449: 463-468.

Lafontaine DLJ, Tollervey D (2006) Ribosomal RNA. In: Encyclopedia of Life Sciences. John Wiley, Chichester, UK: http: //www.els.net/ [10.1038/npg.els.0003832].

Lodhi MA, Reisch BI (1995) Nuclear DNA content of Vitis species, cultivars, and other genera of the Viticeae. Theor Appl Genet 90: 11-16.

Loudet O, Chaillou S, Krapp A, Daniel-Vedele F (2003) Quantitative trait loci analysis of water and anion contents in interaction with nitrogen availability in Arabidopsis thaliana. Genetics 163: 711-722.

Malnoy M, Xu M, Borejsza-Wysocka E, Korban SS, Aldwinckle HS (2008) Two Receptor-like genes, $V f a 1$ and $V f a 2$, confer resistance to the fungal pathogen Venturia inaequalis inciting Apple Scab disease. Mol Plant-Microbe Interact 21: 448-458.

Martin GB, Brommonschenkel SH, Chunwongse J, Frary A, Ganal MW, Spivey R, Wu T, Earle ED, Tanksley SD (1993) Map-based cloning of a protein kinase gene conferring disease resistance in tomato. Science 262: 1432-1436.

Martin GB, Bogdanove AJ, Sessa G (2003) Understanding the functions of plant disease resistance proteins. Annu Rev Plant Biol 54: 23-61.

Merdinoglu D, Wiedeman-Merdinoglu S, Coste P, Dumas V, Haetty S, Butterlin G, Greif C (2003) Genetic analysis of downy mildew resistance derived from Muscadinia rotundifolia. Acta Hort 603: 451-456.

Michelmore RW (2003) The impact zone: genomics and breeding for durable resistance. Curr Opin Plant Biol 6: 397-404.

Michelmore RW, Paran I, Kesseli RV (1991) Identification of markers linked to disease-resistance genes by Bulked Segregant Analysis: a rapid method to detect markers in specific genomic regions by using segregating populations. Proc Natl Acad Sci USA 88: 9828-9832.

Moroldo M, Paillard S, Marconi R, Fabrice L, Canaguier A, Cruaud C, De Berardinis V, Guichard C, Brunaud V, Le Clainche I, Scalabrin S, Testolin R, Di Gaspero G, Morgante M, AdamBlondon AF (2008) A physical map of the heterozygous grapevine 'Cabernet Sauvignon' allows mapping candidate genes for disease resistance. BMC Plant Biol 8: 66.

Mouille G, Witucka-Wall H, Bruyant MP, Loudet O, Pelletier S, Rihouey C, Lerouxel O, Lerouge P, Höfte H, Pauly M (2006) Quantitative trait loci analysis of primary cell wall composition in Arabidopsis. Plant Physiol 141: 1035-1044.

Mur LAJ, Kenton P, Lloyd AJ, Ougham H, Prats E (2008) The hypersensitive response; the centenary is upon us but how much do we know? J Exp Bot 59: 501-520.

Neu C, Stein N, Keller B (2002) Genetic mapping of the Lr20-Pm1 resistance locus reveals suppressed recombination on chromosome arm 7AL in hexaploid wheat. Genome 45: 737-744.

Olmo HP (1986) The potential role of (Vinifera X Rotundifolia) hybrids in grape variety improvement. Experientia 42: 921-926. 
Osoegawa K, Vessere GM, Li Shu C, Hoskins RA, Abad JP, de Pablos B, Villasante A, de Jong PJ (2007) BAC clones generated from sheared DNA. Genomics 89: 291-299.

Pauquet J, Bouquet A, This P, Adam-Blondon A-F (2001) Establishment of a local map of AFLP markers around the powdery mildew resistance gene Run1 in grapevine and assessment of their usefulness for marker assisted selection. Theor Appl Genet 103: 1201-1210.

Peterson DG, Tomkins JP, Frisch DA, Wing RA, Paterson AH (2000) Construction of plant bacterial artificial chromosome (BAC) libraries: An illustrated guide. J Agri Genom 5: Published with permission from CABI Publ. Full text available at http: //www.cabipublishing.org/JAG

Phytowelt $\mathrm{GmbH}$ (2003) Study on the use of the varieties of interspecific vines: final report (Contract No. AGR 30881 of 30/12/2002). Phytowelt for the European Commission: http: //ec.europa.eu/agriculture/markets/wine/studies/vine_en.pdf

Planchon JE (1887) Monographie des Ampelidae vraies. In: Monographia Phanerogamarum A et C de Candolle 5: 305-364.

Riaz S, Dangl GS, Edwards KJ, Meredith CP (2004) A microsatellite marker based framework linkage map of Vitis vinifera L. Theor Appl Genet 108: 864-872.

Riaz S, Doligez A, Henri RJ, Walker MA (2007) Grape. In: C Kole (ed) Genome Mapping and Molecular Breeding in Plants, vol 4: Fruit and Nuts. Springer Berlin, Heidelberg, Germany, pp 63-101.

Riaz S, Tenscher AC, Rubin J, Graziani R, Pao SS, Walker MA (2008) Fine-scale genetic mapping of two Pierce's disease resistance loci and a major segregation distortion region on chromosome 14 of grape. Theor Appl Genet 117: 671-681.

Santos-Rosa M, Poutaraud A, Merdinoglu D, Mestre P (2008) Development of a transient expression system in grapevine via agro-infiltration. Plant Cell Rep 27: 1053-1063.

Savocchia S, Stummer BE, Wicks TJ, van Heeswijck R, Scott ES (2004) Reduced sensitivity of Uncinula necator to sterol demethylation inhibiting fungicides in southern Australian vineyards. Aust Plant Pathol 33: 465-473.

Shen KA, Meyers BC, Islam-Faridi MN, Chin DB, Stelly DM, Michelmore RW (1998) Resistance gene candidates identified by PCR with degenerate oligonucleotide primers map to clusters of resistance genes in lettuce. Mol Plant-Microbe Interact 11: 815-823.

Shizuya H, Birren B, Kim UJ, Mancino V, Slepak T, Tachiiri Y, Simon M (1992) Cloning and stable maintenance of 300-kilobase-pair fragments of human DNA in Escherichia Coli using an F-factor-based vector. Proc Natl Acad Sci USA 89: 8794-8797.

Song J, Dong F, Lilly JW, Stupar RM, Jiang J (2001) Instability of bacterial artificial chromosome (BAC) clones containing tandemly repeated DNA sequences. Genome 44: 463-469.

Stirling B, Newcombe G, Vrebalov J, Bosdet I, Bradshaw HD (2001) Suppressed recombination around the MXC3 locus, a major gene for resistance to poplar leaf rust. Theor Appl Genet 103: 1129-1137.

Suetsugu Y, Minami H, Shimomura M, Sasanuma S, Narukawa J, Mita K, Yamamoto K (2007) End-sequencing and characterization of silkworm (Bombyx mori) bacterial artificial chromosome libraries. BMC Genom 8: 314.

Takken FLW, Albrecht M, Tameling WIL (2006) Resistance proteins: molecular switches of plant defence. Curr Opin Plant Biol 9: 383-390.

van Ooijen G, van den Burg HA, Cornelissen BJC, Takken FLW (2007) Structure and function of resistance proteins in Solanaceous plants. Annu Rev Phytopathol 45: 43-72.

Velasco R, Zharkikh A, Troggio M, Cartwright DA, Cestaro A, Pruss D, Pindo M, Fitzgerald LM, Vezzulli S, Reid J, Malacarne G, Iliev D, Coppola G, Wardell B, Micheletti D, Macalma T, Facci M, Mitchell JT, Perazzolli M, Eldredge G, Gatto P, Oyzerski R, Moretto M, Gutin N, Stefanini M, Chen Y, Segala C, Davenport C, Demattè L, Mraz A, Battilana J, Stormo K, Costa F, Tao Q, Si-Ammour A, Harkins T, Lackey A, Perbost C, Taillon B, Stella A, Solovyev V, Fawcett JA, Sterck L, Vandepoele K, Grando SM, Toppo S, Moser C, Lanchbury J, Bogden R, Skolnick M, Sgaramella V, Bhatnagar SK, Fontana P, Gutin A, Van de Peer Y, Salamini F, Viola R (2007) A high quality draft consensus sequence of the genome of a heterozygous grapevine variety. PLoS ONE 19: e1326. 
Wei F, Gobel-Werner K, Morroll SM, Kurth J, Mao L, Wing RA, Leister D, Schulze-Lefert P, Wise RP (1999) The Mla (powdery mildew) resistance cluster is associated with three NBS-LRR gene families and suppressed recombination within a 240-kb DNA interval on chromosome 5S (1HS) of barley. Genetics 153: 1929-1948.

Welter LJ, Göktürk-Baydar N, Akkurt M, Maul E, Eibach R, Töpfer R, Zyprian EM (2007) Genetic mapping and localization of quantitative trait loci affecting fungal disease resistance and leaf morphology in grapevine (Vitis vinifera L). Mol Breed 20: 359-374.

Wiedemann-Merdinoglu S, Prado E, Coste P, Dumas V, Butterlin G, Bouquet A, Merdinoglu D (2006) Genetic analysis of resistance to downy mildew resistance from Muscadinia rotundifolia 9th Int Conf on Grape Genetics and Breeding. Udine, Italy, 2-6 July 2006.

Woo SS, Jiang JM, Gill BS, Paterson AH, Wing RA (1994) Construction and characterization of a bacterial artificial chromosome library of Sorghum bicolor. Nucl Acids Res 22: $4922-4931$.

Wu CC, Nimmakayala P, Santos FA, Springman R, Scheuring C, Meksem K, Lightfoot DA, Zhang HB (2004) Construction and characterization of a soybean bacterial artificial chromosome library and use of multiple complementary libraries for genome physical mapping. Theor Appl Genet 109: 1041-50.

Zhou F, Kurth J, Wei F, Elliott C, Valè G, Yahiaoui N, Keller B, Somerville S, Wise R, SchulzeLefert P (2001) Cell-autonomous expression of barley Mla1 confers race-specific resistance to the powdery mildew fungus via a Rar1-independent signaling pathway. Plant Cell 13: $337-50$

Zipfel C, Kunze G, Chinchilla D, Caniard A, Jones JD, Boller T, Felix G (2006) Perception of the bacterial PAMP EF-Tu by the receptor EFR restricts Agrobacterium-mediated transformation. Cell 125: 749-760. 